\title{
Kernos
}

Revue internationale et pluridisciplinaire de religion grecque antique

$24 \mid 2011$

Varia

\section{La religion des femmes en Grèce ancienne - Chemin faisant}

\section{André Motte}

\section{(2) OpenEdition \\ Journals}

Édition électronique

URL : http://journals.openedition.org/kernos/1981

DOI : 10.4000/kernos. 1981

ISSN : 2034-7871

\section{Éditeur}

Centre international d'étude de la religion grecque antique

\section{Édition imprimée}

Date de publication : 1 janvier 2011

Pagination : 351-352

ISSN : 0776-3824

\section{Référence électronique}

André Motte, «La religion des femmes en Grèce ancienne - Chemin faisant », Kernos [En ligne], 24 |

2011, mis en ligne le 17 octobre 2011, consulté le 21 septembre 2020. URL : http://

journals.openedition.org/kernos/1981; DOI : https://doi.org/10.4000/kernos.1981 


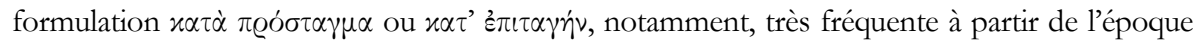
hellénistique, reflète une commande de la divinité, mais ne donne pas d'indice sur le moyen par lequel cette commande a été transmise au dédicant.

En ce qui concerne le monde romain, on notera les contributions de J. Rüpke, qui propose quelques réflexions théoriques sur les dédicaces inscrites, envisagées comme un moyen de communication avec le divin d'une part, et au sein de la communauté humaine d'autre part; P. Poccetti offre une étude des formulaires votifs dans les dédicaces osques et en conclut un manque d'homogénéité de l'utilisation des formulaires et du vocabulaire dans ces inscriptions, tant privées que publiques, contrairement à l'épigraphie qui s'inscrit dans le cadre des travaux publics; C.R. Galvao-Sobrinho, à travers l'étude du lis fullonum, procès dirigé contre un collège de foulons pour l'occupation d'un territoire sans payer les taxes légales, étudie les relations entre dédicaces et espace public; M. Buonocore rassemble un catalogue de 191 dédicaces provenant de l'Italie centrale et apennine; G.L. Gregori réunit les attestations du culte des divinités portant l'épithète Augustus/a; C. Machado étudie la fonction et la signification des dédicaces païennes dans l'Antiquité tardive; $\mathrm{O}$. de Cazanove étudie les ex-voto anatomiques portant une inscription ou accompagnés d'une dédicace; enfin, L. Chioffi rassemble le corpus des dédicaces aux Dis Manibus qui ne présentent pas un caractère funéraire, en actualisant la liste proposée par le CIL VI.

Par la variété d'études de cas et la qualité de ses contributions, l'ouvrage montre l'intérêt que représente une étude globale et systématique de cette catégorie de documents pour notre connaissance des systèmes religieux et, en particulier, des relations que les humains établissent avec le divin d'une part, et au sein de leur propre communauté d'autre part. Il faut toutefois nuancer quelque peu la distinction tranchée qui ressort de certaines communications entre les motivations religieuses et "profanes » qui sous-tendent ces pratiques dédicatoires, qui ne sont pas le reflet d'une seule volonté d'autoreprésentation. L'articulation entre les deux aspects, social et religieux, semble en réalité plus complexe, et il ne faut pas forcément chercher à sousestimer l'un au profit de l'autre. Il reste à espérer que ce volume stimulant à bien des égards pourra encourager davantage la recherche sur ces documents.

Stéphanie Paul

(F.R.S.-FNRS - Université de Liège)

Lydie BODIOU, Véronique MEHL (éds), La religion des femmes en Grèce ancienne. Mythes, cultes et société, Rennes, Presses universitaires de Rennes, 2009. 1 vol. 15,5 $\times 24 \mathrm{~cm}, 281$ p. (Collection « Histoire »). ISBN : 978-2-7535-0882-8.

Lydie Bodiou, Véronique MeHL, Jacques OulHen, Francis Prost, Jérôme WILGauX (dir.), Chemin faisant. Mythes, cultes et société en Grèce ancienne. Mélanges en l'honneur de Pierre Brulé, Rennes, Presses universitaires de Rennes, 2009. 1 vol. 15,5 × $24 \mathrm{~cm}, 314$ p. (Collection « Histoire »). ISBN : 978-2-7535-0946-7.

C'est bien une présentation groupée qu'appellent ces deux ouvrages parus la même année, non seulement parce qu'ils ont en commun deux directeurs scientifiques et sont issus des mêmes Presses, mais aussi parce qu'ils sont destinés l'un et l'autre à rendre hommage à un maitre apprécié et bien connu des fervents de religion grecque, Pierre Brulé, professeur à l'Université de Rennes, admis à la retraite à l'automne 2008. Le contenu des deux volumes ayant été détaillé dans le numéro 23 de Kernos (p. 412-413), on se bornera ici à quelques indications de portée générale. Le premier volume reproduit les actes d'un colloque organisé en juillet 2008, à Cork en terre irlandaise, par le CRESCAM et le Celtic Conference in Classics, pour célébrer le vingtième anniversaire de la parution de La fille d'Athènes. Treize collègues, 
amis ou élèves, y ont pris part, auxquels il faut ajouter P.B. lui-même, auteur, comme on sait, de ce maitre-ouvrage. Leurs contributions concernent donc exclusivement la religion grecque dans ses composantes féminines; une bibliographie sélective, mais riche, est suivie de plusieurs index. Le second ouvrage, explicitement dédié au père de La fille d'Athènes déborde quelque peu le domaine religieux; il compte une vingtaine d'articles centrés sur trois thèmes principaux entre lesquels apparaissent souvent des recoupements : les femmes, la religion et les corps. Inauguré par une biographie "non autorisée », il se termine par la bibliographie du dédicataire.

Placés sous le signe de l'amitié, les deux ouvrages procèdent d'une même intention : saluer l'homme et l'helléniste en suivant des voies qu'il a lui-même tracées, qu'ils s'agisse des thématiques, comme la religion des femmes, le polythéisme, l'esclavage, ou des démarches, volontiers tournées vers le concret et marquant une prédilection pour la Grèce buissonnière (cf. le c.r. du dernier ouvrage de P.B., La Grèce d'à côté, dans Kernos, 21 [2008], p. 357-359). Sous ce rapport notamment, les deux parcours sont très réussis. Nul ne pourrait se méprendre, en effet, sur l'identité du dieu auquel est voué le kernos d'offrandes que dessinent ces belles études. Ad multos annos, ajouterai-je, en m'associant cordialement à l'hommage rendu.

André Motte (Université de Liège)

Joannis Mylonopoulos (éd.), Divine Images and Human Imaginations in Ancient Greece and Rome, Leiden/Boston, Brill, 2010. 1 vol. 16,5 × 24,5 cm., ill., 437 p., (Religions in the Graeco-Roman World, 170). ISBN : 978-90-04-17930-1.

Issu en grande partie d'un colloque qui s'est déroulé à l'Université d'Erfurt en 20071, ce volume réunit treize études consacrées aux représentations figurées du divin dans les mondes grec (surtout) et romain, et aux différents problèmes que pose aux savants modernes l'interprétation des images des dieux antiques. C'est à signaler ces problèmes que s'attache l'introduction de J. Mylonopoulos, qui ne se limite pas à passer en revue les diverses contributions, mais les intègre dans un riche tissu argumentatif en ouvrant des pistes de réflexion susceptibles de renouveler l'enquête. Organisé suivant un axe à la fois chronologique et thématique, le volume est inauguré par une étude de F. Blakolmer portant sur les images divines dans l’iconographie minoenne et mycénienne; l'A. interroge le décalage problématique entre, d'un côté, le panthéon pleinement articulé dont témoignent les documents écrits et, de l'autre, les représentations figurées des dieux : l'interprétation de ces dernières s'avère extrêmement difficile à cause de la quasi-indistinction entre l'humain et le divin, et de la quasi-absence d'attributs spécifiques, sans oublier les malentendus engendrés par la place prépondérante des images féminines. Ainsi, le déchiffrement du Lineaire $\mathrm{B}$ nous a révélé entre autres choses à quel point nous sommes loin de posséder d'emblée, comme on le croyait autrefois, les clés pour « déchiffrer» l'iconographie de l'âge du Bronze. D'autre part, la neutralité iconique qui s'y trouve privilégiée lorsqu'il est question de mettre en images les dieux, ou bien le roi, est un choix significatif, même si son sens exact reste à découvrir. La place de l'aniconisme dans la représentation du divin en Grèce ancienne fait l'objet de l'étude de M. Gaifman, qui en parcourt les interprétations, de Winckelmann à Nilsson, de Pausanias à Clément d'Alexandrie; concernant la construction culturelle de ce qu'on appelle « aniconisme », l'A. signale à raison la distance entre le point de vue de Pausanias, selon lequel la (prétendue) ancienneté des représentations « aniconiques » se trouvait positivement qualifiée en termes de prestige religieux, et celui des savants modernes qui en jugeant l'aniconisme à l'aune d'un paradigme anthropomorphique et dans une perspective évolutionniste, l'ont disqualifié comme étant «primitif». Le statut de korai archaï-

${ }^{1}$ Le sommaire du volume est donné dans Kernos 23 (2010), p. 415. 